\title{
Cognitive function in Type 1 (insulin-dependent) diabetic patients after nocturnal hypoglycaemia
}

\author{
I. Bendtson ${ }^{1}$, J. Gade ${ }^{2}$, A. Theilgaard ${ }^{3}$ and C.Binder ${ }^{1}$ \\ ${ }^{1}$ Steno Diabetes Center, Gentofte, \\ ${ }^{2}$ Department of Medical Informatics and Image Analysis, Aalborg University, Aalborg, \\ ${ }^{3}$ Department of Clinical Psychology, Rigshospitalet, State University Hospital Copenhagen, Denmark
}

\begin{abstract}
Summary. Eight Type 1 (insulin-dependent) diabetic patients with no diabetic complications were studied on two consecutive and one subsequent overnight occasions. The aim was to evaluate the influence of nocturnal hypoglycaemia on neuropsychological and reaction time tests the following morning. Hypoglycaemia was induced by i.v. insulin infusion, blood glucose nadir was $1.5 \pm 0.3 \mathrm{mmol} / \mathrm{l}$. Duration of hypoglycaemia (blood glucose $<3 \mathrm{mmol} / \mathrm{l}$ ) was $101 \pm 38 \mathrm{~min}$. Whole night sleep statistics for all patients showed no statistical differences between the normoglycaemic and hypoglycaemic nights, however, there was a tendency of prolongation of the second sleep cycle in the nights with hypoglycaemia. Each patient was used as his own control and periods with blood glucose concentration less than
\end{abstract}

$3 \mathrm{mmol} / \mathrm{l}$ were compared to exactly the same periods in nights with blood glucose level over $5 \mathrm{mmol} / \mathrm{l}$. During hypoglycaemia the amount of deep sleep was reduced and replaced by superficial sleep and arousals of short duration. Further, the reduction in deep sleep was replaced later at night. Neuropsychological test scores and reaction time measurements in the morning showed no differences between the normoglycaemic and hypoglycaemic nights. In conclusion; despite sleep disturbances, nocturnal hypoglycaemia did not impair cognitive function the following morning in Type 1 (insulin-dependent) diabetic patients.

Key words: Nocturnal hypoglycaemia, sleep disturbances, cognitive function.
Cognitive dysfunction has been found during acute hypoglycaemia in healthy subjects as well as in diabetic patients [1-3]. The duration of the acute impact on brain function has been shown to be less than $1 \mathrm{~h}$ after restoration of the glycaemic level [1-3]. Permanent cognitive dysfunction has been described in adult diabetic patients with recurrent episodes of severe hypoglycaemia [4]. Children seem to be particularly vulnerable, in that adolescents who have had episodes of severe hypoglycaemia before the age of 5 years show neuropsychological and electroencephalographic (EEG) abnormalities $[5,6]$. We have reported minor sleep disturbances and transitory EEG changes in insulin-dependent diabetic patients during nocturnal insulin-induced hypoglycaemia $[7,8]$. Patients with obstructive sleep apnea leading to mild nocturnal hypoxaemia showed impairment in neuropsychological tests and car-driving performance [9, 10]. Simple reaction time test as an objective measure of vigilance was impaired the following morning in patients with sleep apnea [11]. Sleep deprivation without metabolic alterations has been shown to reduce the performances in vigilance tests [12] and to increase the reaction time in simple tests [13].
Since nocturnal hypoglycaemia induces sleep disturbances and EEG changes and acute hypoglycaemia is accompanied by reduced performance abilities, we expect an impact on cerebral performance in the mornings following nocturnal hypoglycaemia. In order to test this hypothesis, we have studied eight Type 1 (insulin-dependent) diabetic men by neurophysiological tests and reaction time measurements after normoglycaemia and hypoglycaemic sleep.

\section{Patients and methods}

Eight Type 1 diabetic men participated in the study. Clinical characteristics of the patients are shown in Table 1. All patients had urine albumin excretions less than $30 \mathrm{mg} / 24 \mathrm{~h}$, serum-creatinine less than $110 \mu \mathrm{mol} / \mathrm{l}$, blood pressure less than $120 / 80 \mathrm{~mm} \mathrm{Hg}$, and normal resting ECG. No patients showed signs of retinopathy or neuropathy. None had any history of epilepsy or other neurological disturbances. No medication other than insulin was taken. All had, prior to the present study, participated in other studies on insulin-induced hypoglycaemia.

All the patients gave their informed consent. The study was approved by the regional Ethics Committee. 
Table 1. Patients' characteristics

\begin{tabular}{llclll}
\hline Patient & $\begin{array}{l}\text { Age } \\
\text { (years) }\end{array}$ & $\begin{array}{l}\text { Diabetes } \\
\text { duration } \\
\text { (years) }\end{array}$ & $\begin{array}{l}\text { BMI } \\
\left(\mathrm{kg} / \mathrm{m}^{2}\right)\end{array}$ & $\begin{array}{l}\text { Insulin dose } \\
(\mathrm{IU} / \mathrm{kg})\end{array}$ & $\begin{array}{l}\mathrm{HbA} 1_{\mathrm{c}} \\
(\%)\end{array}$ \\
\hline 1 & 22 & 8 & 25.0 & 0.8 & 8.5 \\
2 & 27 & 4 & 19.0 & 0.7 & 7.5 \\
3 & 40 & 4 & 24.3 & 0.9 & 7.4 \\
4 & 28 & 6 & 30.0 & 0.3 & 8.3 \\
5 & 48 & 26 & 21.0 & 0.4 & 7.0 \\
6 & 24 & 5 & 22.4 & 0.6 & 8.4 \\
7 & 31 & 27 & 21.9 & 0.5 & 7.5 \\
8 & 28 & 8 & 22.3 & 0.4 & 7.0 \\
\hline Mean & 31 & 11 & 23.2 & 0.6 & 7.7 \\
\hline
\end{tabular}

Table 2. Hypoglycaemia

\begin{tabular}{|c|c|c|c|c|}
\hline \multirow[t]{2}{*}{ Patient } & \multirow[t]{2}{*}{$\begin{array}{l}\text { Nadir } \\
(\mathrm{mmol} / \mathrm{l})\end{array}$} & \multirow[t]{2}{*}{$\begin{array}{l}\text { Time } \\
\text { for nadir }\end{array}$} & \multicolumn{2}{|c|}{$\begin{array}{l}\text { Duration of } \\
\text { hypoglycaemia(min) }\end{array}$} \\
\hline & & & $<2 \mathrm{mmol} / \mathrm{l}$ & $<3 \mathrm{mmol} / 1$ \\
\hline \multicolumn{5}{|l|}{ Night 2} \\
\hline 1 & 2.5 & 4.45 & 0 & 120 \\
\hline 2 & 1.3 & 2.45 & 60 & 60 \\
\hline 3 & 1.8 & 3.15 & 45 & 75 \\
\hline 4 & 1.9 & 3.15 & 30 & 120 \\
\hline 5 & 1.3 & 5.00 & 60 & 135 \\
\hline 6 & 1.6 & 2.45 & 60 & 110 \\
\hline 7 & 1.2 & 3.00 & 30 & 60 \\
\hline 8 & 1.3 & 2.45 & 45 & 135 \\
\hline Mean \pm SD & $1.6 \pm 0.4$ & & $41 \pm 21$ & $101 \pm 37$ \\
\hline \multicolumn{5}{|l|}{ Night 3} \\
\hline 1 & 1.8 & 3.30 & 45 & 180 \\
\hline 2 & 1.1 & 2.45 & 75 & 120 \\
\hline 3 & 1.2 & 4.00 & 60 & 120 \\
\hline 4 & 1.8 & 3.00 & 20 & 45 \\
\hline 5 & 1.4 & 3.30 & 40 & 80 \\
\hline 6 & 1.5 & 2.30 & 60 & 130 \\
\hline 7 & 1.1 & 3.15 & 20 & 60 \\
\hline 8 & 1.3 & 3.15 & 30 & 60 \\
\hline Mean \pm SD & $1.4 \pm 0.3$ & & $43 \pm 18$ & $99 \pm 44$ \\
\hline
\end{tabular}

\section{Study design}

All the patients participated for three nights. Primarily a night without hypoglycaemia, consecutively a night with insulin-induced hypoglycaemia, subsequently followed by a third night with insulin-induced hypoglycaemia. We have not previously demonstrated a first night effect in patients who were familiar with studies on hypoglycaemia. However, to exclude a possible influence on the hypoglycaemic nights, we chose the first night for the patients to be normoglycaemic. Serum-cortisol was used as a marker of the stress level.

The patients were admitted to the sleep laboratory at 22.00 hours after a normal working day without prescribed changes in diet or physical activity. Intermediate acting insulin was omitted before either dinner or before bedtime or both. On arrival at the hospital two cannulas were inserted into contralateral antecubital veins; the cannula for blood sampling was heparinized and the other kept patent with a $154 \mathrm{mmol} / \mathrm{NaCl}$ infusion containing Velosulin Human $100 \mathrm{IU} / \mathrm{ml}$ (Novo Nordisk, Basgsværd, Denmark). Insulin infusion was given by an insulin pump (Imed, Oxford, UK). The pump used a $60 \mathrm{ml}$ syringe containing $154 \mathrm{mmol} / 1 \mathrm{NaCl}$ and $15 \mathrm{IU}$ insulin, equivalent to an insulin concentration of $0.25 \mathrm{IU} / \mathrm{ml}$. Infusion rates were dependent on the actual blood glucose concentration. The ideal was to have blood glucose stabilized at about $6 \mathrm{mmol} / \mathrm{l}$. On the nights here insulin-induced hypoglycaemia were performed, the insulin infusion rate was increased at 01.30 hours. The blood glucose level should decrease to under $2.0 \mathrm{mmol} / \mathrm{l}$ over $1-2 \mathrm{~h}$, and then be stabilized at that level for around $1 \mathrm{~h}$. Thereafter $10 \mathrm{~g}$ glucose was injected i. v. and the blood glucose concentration was increased to $6 \mathrm{mmol} / \mathrm{l}$ for the rest of the night. Blood was drawn every 30 min during stabilization. From the time when the infusion rate was increased to cause hypoglycaemia blood was drawn every $15 \mathrm{~min}$ until the blood glucose level was re-established.

The blood glucose target in the mornings was above $4 \mathrm{mmol} / 1$ to ensure that neuropsychological testings were not performed during hypoglycaemia. Neuropsychological testings were made right after awakening and removal of electrodes in the morning at 07.00 hours. All testing was conducted by the same investigator (IB).

\section{Analytical methods}

Venous blood glucose concentrations were measured in duplicate; bedside with an oxidase method (Hypocount Mx-B, BM-Test-BG; Boehringer-Mannheim, Mannheim, FRG) and later with a dehydrogenase method (Cobas Mira; Hoffmann la Roche, Basel Switzerland). Results from the Cobas-analysis are presented.

Blood for measurements of serum cortisol was centrifuged for $10 \mathrm{~min}$ and separated immediately. Serum samples were stored at $20^{\circ} \mathrm{C}$. Cortisol was measured by a commercial kit (Kingo Diagnostica, Copenhagen, Denmark).
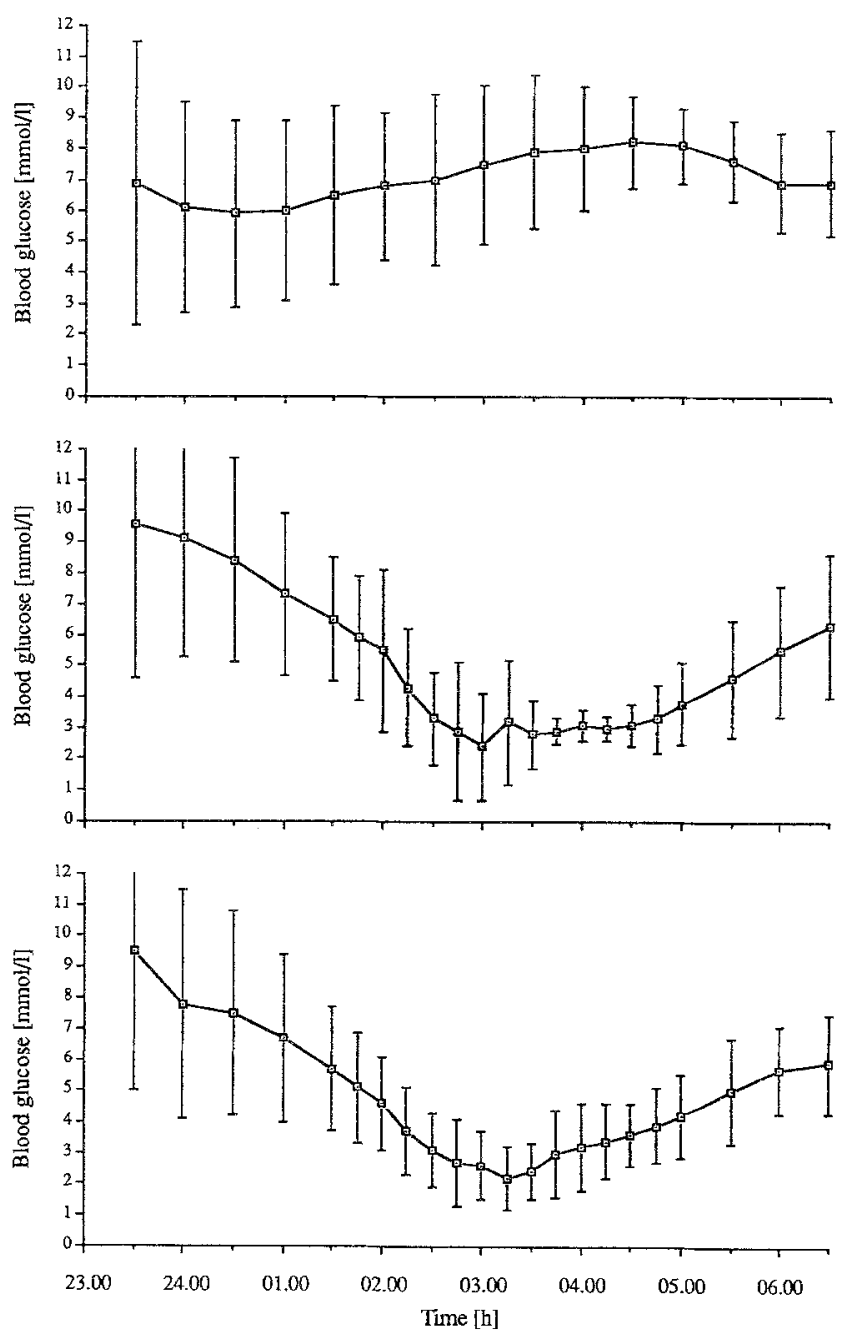

Fig. 1. Blood glucose concentrations (mean \pm SD) for all patients. Upper panel: night 1; middle panel: night 2; lower panel: night 3 
Table 3. Whole night sleep statistics

\begin{tabular}{llll}
\hline & Night 1 & Night 2 & Night 3 \\
\hline Total sleep period (min) & $347(40)$ & $355(27)$ & $350(32)$ \\
Total sleep time (min) & $319(45)$ & $328(35)$ & $315(31)$ \\
Sleep efficiency (\%) & $91.2(4.9)$ & $92.1(3.8)$ & $90.5(3.5)$ \\
NREM-2 latency (min) & $18(21)$ & $11(15)$ & $6(8)$ \\
REM latency (min) & $89(63)$ & $68(37)$ & $96(94)$ \\
AWAKE (\% of TSP) & $9.5(5.5)$ & $9.0(3.9)$ & $11.1(4.1)$ \\
NREM-1 & $14.9(6.7)$ & $11.1(6.1)$ & $16.5(8.3)$ \\
NREM-2 & $41.5(13.4)$ & $49.6(14.9)$ & $46.7(14.6)$ \\
NREM-3 + & $17.5(8.3)$ & $11.3(8.8)$ & $15.4(7.3)$ \\
REM & $17.6(5.3)$ & $18.8(6.2)$ & $15.4(4.8)$ \\
Cycle 1 time (min) & $101(59)$ & $92(56)$ & $128(87)$ \\
Cycle 2 time (min) & $101(27)$ & $113(45)$ & $143(50)$ \\
Wake after sleep onset & & & \\
$<3-m i n$ duration & 11 & 10 & 11 \\
$>$ 3-min duration & 3 & 2 & 4 \\
\hline
\end{tabular}

Figures are mean and (SD)

TSP, total sleep period;

NREM-1: stage 1, superficial sleep, alpha activity abates;

NREM-2: stage 2, normal sleep, slow waves $<20 \%$ of the time;

NREM-3: stage 3, deep sleep, slow waves $20-50 \%$;

NREM-4: stage 4, deep sleep, slow waves $>50 \%$;

REM: dream sleep, low voltage electroencephalogram with mixed frequencies, eye movements and low muscle tone;

Cycle, time from the end of one REM period to the end of the following

\section{Recordings}

Electroencephalogram (EEG) was recorded using surface electrodes. The two EEG channels were the standard derivations for sleep analysis, C3-A2 and C4-A1 [14]. Submental chin electromyogram (EMG) was registered via prefilled disposable electrodes.

The eye movements, actooculogram (AOG) were measured using a piezoceramic mechanical sensor (Siemens E232E, Siemens, Münich, FRG). The frequency range for the EEG and AOG channels was $0.3-70 \mathrm{~Hz}$ and $20-700 \mathrm{~Hz}$ for the EMG. All recordings were continuously registered on a Siemens-Elema Mingograph, (Siemens-Elema AB, Solna, Sweden). The recordings were stored on a Teac XR 510 frequency modulated tape recorder, (Teac Corp., Toyko, Japan).

\section{Analysis}

Analysis of the recordings was made off-line using a polygraphic sleep analysis system (Nightingale; Judex Datasystems, Aalborg, Denmark). The setup and analysis used has been described previously [7].

The sleep data were registered for epochs of $30 \mathrm{~s}$ duration. Periods with blood glucose below $3 \mathrm{mmol} / \mathrm{l}$ were compared to exactly the same time-periods on night 1 , where the blood glucose was above $5 \mathrm{mmol} / \mathrm{l}$, during these periods sleep stages including awakenings were counted. Each patient was used as his own control, however, mean values were also calculated.

\section{Neuropsychological tests}

The three tests most sensitive and least influenced by the learning effect concerning short-term memory, attention and concentration were selected for use from the test battery constructed for acute hypoglycaemia [1]. The patients were presented with a set of tests before the first real test stimulation. Different test sets were used at each test to exclude direct recognition, and the tests were performed in random order.

Test results are multifactorially dependent on e.g. education, level of exertion, employment, alcohol consumption, recurrent severe episodes of hypoglycaemia [4-6] and age at diabetes onset [4, 5]. This emphasizes the need for the individual patient to act as his own control.

Trail making: (1) The subjects were asked to connect the numbers 1-25. (2) Connection should be made between letters (A-L) and numbers [1-12] alternately in the correct order. The test calls for attention, visual scanning and planning and is scored as the number of seconds needed to complete the task.

Digit span: The subjects were asked to repeat digits either forwards or backwards in the sequence presented verbally. This is a test of attention and short-term memory. The score is the highest number of digits repeated correctly.

Letter cancellation: Patients were presented with unbroken rows of letters and should cancel, A, B, N, and $\mathrm{P}$ as fast as possible for $3 \mathrm{~min}$. The test requires rapid discrimination of details and measures attention and distractibility. The score is the number of letters read and the number of errors.

Visual reaction time: The test was performed using the Somnolog system (Ventec Aps, Hellerup, Denmark). We used two of the built-in reaction time tests, where the light stimuli are given either by a light emitting diode or a liquid crystalline display. In both tasks the reaction time is measured as the time from light on until the patients push a button. The optical stimuli are given randomly with intervals of 1 to $4 \mathrm{~s}$. For each task the mean value and SD of 100 reaction times were determined and the number of false reactions were registered.

\section{Statistical analysis}

Values are mean \pm SD or (ranges) or both. Wilcoxon's rank sum test for paired data were used for the analysis of the sleep statistics. Friedman two-way analysis by ranks for paired data with multiple comparisons between nights were used for the analyses of the neurophysiological results. $p<0.05$ is considered statistically significant.

\section{Results}

Mean blood glucose profiles for all patients are shown in Figure 1. The nadir in blood glucose concentration, time for the hypoglycaemic periods and their duration are presented in Table 2 for the individual patients on the two nights. The minimum values for blood glucose were, except for two patients (number 1 and 3 ), the same on the hypoglycaemic nights. There were some differences in the time for nadir to occur and the total duration of the hypoglycaemic periods.

Serum cortisol at 23.30 hours after insertion of i.v. catheters and placement of electrodes were $125 \pm 75$ $(42-265) \mathrm{nmol} / 1$ on the first night compared to $164 \pm 106$ $(82-397) \mathrm{nmol} / \mathrm{l}$ and $156 \pm 108(37-397) \mathrm{nmol} / \mathrm{l}$ on the second and third nights, respectively (NS).

Whole night sleep statistics are shown in Table 3. No significant differences were found between the normoglycaemic and hypoglycaemic nights. However, there was a tendency toward prolongation of the second sleep cycle, which occurred at the time of the night when the blood glucose was low. Comparisons between the specific hypoglycaemic and normoglycaemic periods of the nights are shown in Table 4 as a percentage of the observed period. 
Table 4. Sleep statistics

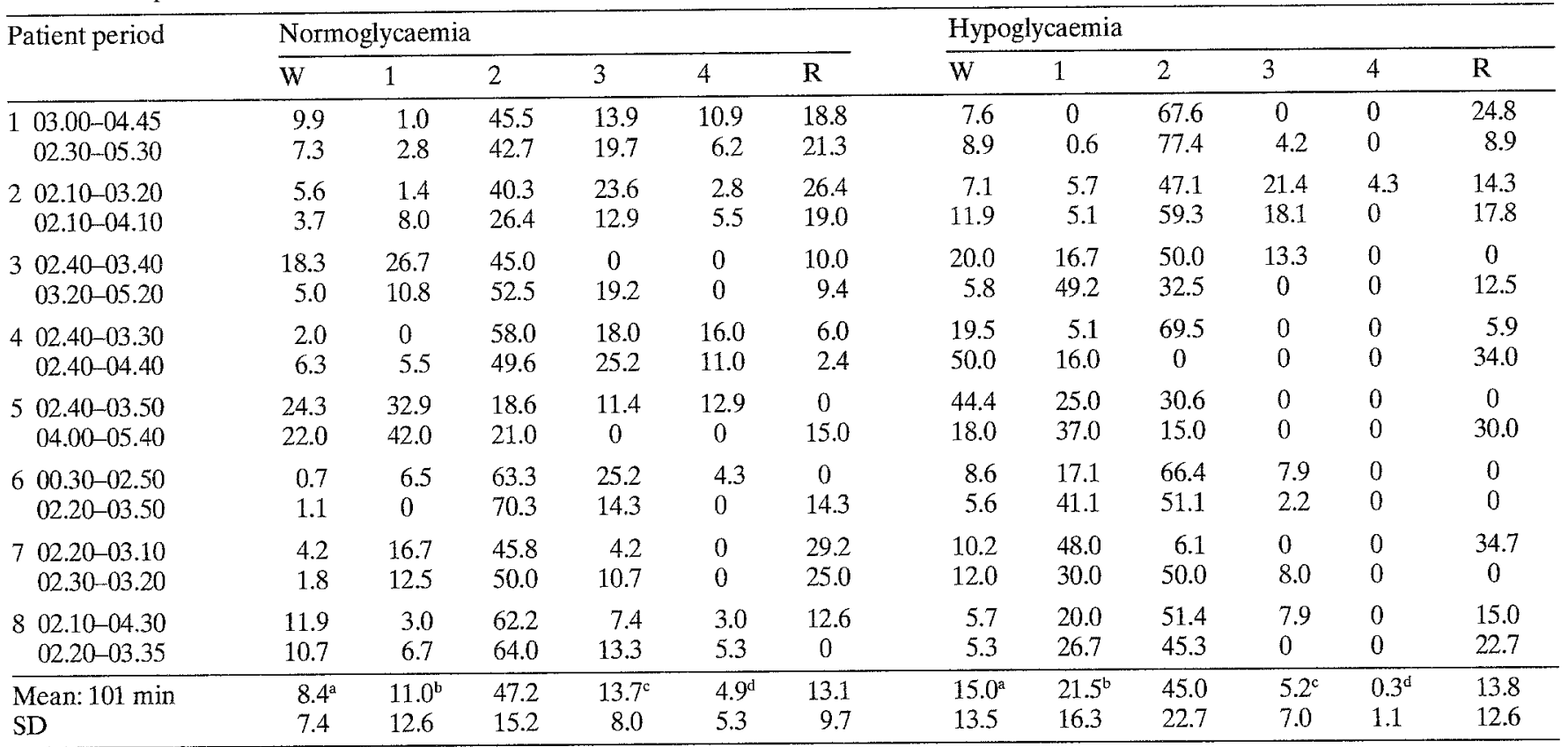

Figures are \% of the observed period.

Time periods with hypoglycaemia (blood glucose $<3.0 \mathrm{mmol} / \mathrm{l}$ ) are for each patient compared with the same period on a night with blood glucose level above $5 \mathrm{mmol} / \mathrm{l} .{ }^{\mathrm{a}} p<0.04 ;{ }^{\mathrm{b}} p<0.03$;

On the hypoglycaemic nights significantly more time was spent awake and in stage 1 sleep with a concomitant decrease in deep sleep (stage 3 and 4). No differences were found in the amount of stage 2 sleep or rapid eye movement (REM) sleep. Patients number 1, 3 and 6 doubled their numbers of short awakenings (duration less than 3 min) during hypoglycaemia compared to normoglycaemia but this did not reach statistical difference nor did awakenings with a duration of more than $3 \mathrm{~min}$.

Blood glucose concentrations during neuropsychological testings were performed were: night 1 , normo-

Table 5. Neuropsychological tests

\begin{tabular}{|c|c|c|c|c|c|c|c|c|}
\hline Patient & 1 & 2 & 3 & 4 & 5 & 6 & 7 & 8 \\
\hline L1 & $\begin{array}{r}453 \\
52\end{array}$ & $\begin{array}{r}510 \\
12\end{array}$ & $\begin{array}{r}377 \\
19\end{array}$ & $\begin{array}{r}427 \\
11\end{array}$ & $\begin{array}{r}374 \\
23\end{array}$ & $\begin{array}{r}383 \\
14\end{array}$ & $\begin{array}{r}469 \\
21\end{array}$ & $\begin{array}{r}384 \\
17\end{array}$ \\
\hline L 2 & $\begin{array}{r}345 \\
13\end{array}$ & $\begin{array}{r}393 \\
18\end{array}$ & $\begin{array}{r}348 \\
12\end{array}$ & $\begin{array}{r}328 \\
5\end{array}$ & $\begin{array}{r}360 \\
24\end{array}$ & $\begin{array}{r}373 \\
1\end{array}$ & $\begin{array}{r}628 \\
23\end{array}$ & $\begin{array}{r}384 \\
9\end{array}$ \\
\hline L 3 & $\begin{array}{r}345 \\
12\end{array}$ & $\begin{array}{r}480 \\
8\end{array}$ & $\begin{array}{r}393 \\
11\end{array}$ & $\begin{array}{r}393 \\
2\end{array}$ & $\begin{array}{r}384 \\
12\end{array}$ & $\begin{array}{r}412 \\
4\end{array}$ & $\begin{array}{r}657 \\
22\end{array}$ & $\begin{array}{r}375 \\
3\end{array}$ \\
\hline D 1 & 9 & 9 & 9 & 10 & 11 & 11 & 10 & 11 \\
\hline D 2 & 8 & 10 & 10 & 9 & 8 & 9 & 8 & 11 \\
\hline D 3 & 8 & 10 & 10 & 9 & 9 & 11 & 9 & 12 \\
\hline $\mathrm{T} 1$ & 247 & 136 & 176 & 151 & 167 & 201 & 223 & 169 \\
\hline Т 2 & 209 & 130 & 240 & 151 & 164 & 172 & 213 & 150 \\
\hline T 3 & 188 & 152 & 213 & 177 & 170 & 193 & 173 & 135 \\
\hline
\end{tabular}

Figures refer to the three nights; 1 was normoglycaemic, on nights 2 and 3 hypoglycaemia was induced.

$\mathrm{L}$, Letter cancellation, upper row is number of letters read, underneath number of errors; D, digit span in total: forward + backwards; $\mathrm{T}$, trail making $\mathrm{A}+\mathrm{B}(\mathrm{s})$
${ }^{\mathrm{c}} p<0.007 ;{ }^{\mathrm{d}} p<0.004$.

W, Awake; 1, NREM stage 1; 2, NREM stage 2; 3, NREM stage3; 4 , NREM stage $4 ; R, R E M$, dream sleep

glycaemia: $6.8 \pm 1.7(5.8-8.7) \mathrm{mmol} / \mathrm{l}$, night 2 , post-hypoglycaemic: $6.0 \pm 1.8(4.4-9.4) \mathrm{mmol} / 1$ and night 3 , posthypoglycaemic: $6.0 \pm 1.6(4.1-8.3) \mathrm{mmol} / \mathrm{l}$. Results from the neuropsychological tests are shown in Table 5. There were no statistically significant differences in the test scores between the normoglycaemic (night 1 ) and the two hypoglycaemic nights (2 and 3 ). However, as shown in Table 5 , there was great variance in the performance in the three tests for the individual patient, for instance; poorer performance in letter cancellation and improvement in trail making and vice versa. Likewise, there were no statistical differences in the test scores for the reaction times, shown in Table 6.

There are no correlations between the test scores and time for hypoglycaemic nadir, duration of hypoglycaemia, or the level of hypoglycaemia (Tables 2,5 and 6). Neither were there correlations between number of awakenings during hypoglycaemia and the test scores.

\section{Discussion}

In the present study we found insulin-dependent diabetic patients neuropsychologically unaffected in the mornings following nocturnal hypoglycaemia. This is in accordance with previous investigations during daytime in diabetic patients, which showed a normalisation of the cerebral dysfunction less than $1 \mathrm{~h}$ after restored glycaemic level [1-3]. However, during nocturnal hypoglycaemia the sleep was disturbed to a degree which might be another cause of reduction of neuropsychological performance in the morning [9-13]. Normally in studies on healthy subjects who are unfamiliar with test situations, laboratory facilities etc, sleep is disturbed during the first night. The dis- 
Table 6. Reaction time

\begin{tabular}{lrrrrrrrr}
\hline Patient 1 & 2 & 3 & 4 & 5 & 6 & 7 & 8 \\
\hline LED & & & & & & & & \\
$\mathrm{n} 1$ & 309 & 238 & 238 & 266 & 287 & 218 & 243 & 212 \\
& 99 & 45 & 45 & 70 & 56 & 39 & 54 & 36 \\
& 1 & 2 & 2 & 1 & 0 & 1 & 0 & 0 \\
$\mathrm{n} 2$ & 301 & 236 & 247 & 289 & 284 & 240 & 276 & 204 \\
& 106 & 61 & 55 & 90 & 50 & 61 & 100 & 37 \\
& 1 & 2 & 1 & 3 & 0 & 1 & 1 & 1 \\
$\mathrm{n} 3$ & 291 & 244 & 222 & 296 & 275 & 242 & 241 & 202 \\
& 77 & 42 & 46 & 78 & 51 & 87 & 75 & 24 \\
& 3 & 5 & 1 & 0 & 0 & 2 & 1 & 1 \\
\hline LCD & & & & & & & & \\
$\mathrm{n} 1$ & 338 & 295 & 291 & 282 & 332 & 243 & 264 & 247 \\
& 92 & 76 & 72 & 69 & 66 & 53 & 119 & 42 \\
& 0 & 0 & 2 & 1 & 0 & 0 & 4 & 1 \\
$\mathrm{n} 2$ & 310 & 274 & 282 & 335 & 333 & 273 & 243 & 245 \\
& 87 & 44 & 96 & 133 & 59 & 56 & 54 & 67 \\
& 2 & 1 & 2 & 1 & 2 & 0 & 0 & 1 \\
$\mathrm{n} 3$ & 325 & 313 & 266 & 345 & 308 & 302 & 248 & 249 \\
& 72 & 92 & 85 & 109 & 62 & 133 & 76 & 104 \\
& 1 & 1 & 2 & 2 & 0 & 2 & 2 & 3 \\
\hline
\end{tabular}

LED, Light emitting diode; LCD, liquid crystalline display; n1-3, night 1 without hypoglycaemia, 2 and 3 with hypoglycaemia.

For each night are shown: Upper row: mean values of 100 reaction times in (ms). Second row: SD from the mean values. Third row: number of false reactions

turbances found are a longer period to sleep onset, superficial sleep with more arousals, resulting in reduced amount of deep sleep and a reduction in sleep efficiency. In the current study, a longer time period to the first stage 2 sleep on the normoglycaemic night was found although there was a variation; four patients showed a decrease in latency from the first to the second nights while three showed an increase and one had no difference. Moreover, the time to sleep onset was identical and the sleep efficiency was not different on the three nights. Furthermore, there were no differences in the patients' stress levels on the three nights as evaluated by their cortisol levels. Thus, in accordance with our previous findings a first night effect or habituation to the sleep laboratory did not occur $[7,8]$. We have previously described a prolongation of the two first sleep cycles on nights with hypoglycaemia in diabetic patients [7]. In some of the patients we detected EEG-changes with specific patterns for hypoglycaemia. The hypoglycaemic frequencies were between 4 and $6 \mathrm{~Hz}[8]$, which is in the theta frequency range. Theta activity would be expected to be present in different amounts in all sleep stages including REM [14]. Thus, hypoglycaemic sleep alterations could be concealed in the normal sleep patterns. This is consistent with the present whole night sleep statistics, in which we were unable to find statistical differences among the sleep stages. However, in whole night sleep statistics it is not possible to exclude differences within a certain period. Normally, deep sleep dominates at the beginning of the night and then during the night REM periods of gradually increasing length appear with concomitant shortening of the intervals [15]. Thus, the only possible way to compare hypogly- caemic and non-hypoglycaemic sleep is to compare exactly the same time period for the different nights. During normoglycaemia normal sleep patterns were present in all patients, confirming the description of sleep patterns mentioned above. Hypoglycaemia alters the sleep patterns with a reduction of slow wave sleep replaced by superficial stage 1 sleep and awakefulness. However, awakefulness was actually only arousals with a duration of less than 3 minutes. Some of the patients (numbers 1, 3 and 6) did increase their number of arousals, while the others seemed unaffected. The reduction in deep sleep during hypoglycaemia, $5.5 \%$ vs $18.6 \%$, was replaced later at night ending up with $13.4 \%$ deep sleep on hypoglycaemic nights compared to $17.5 \%$ on normoglycaemic nights. Thus, the patients were able to catch up the missed slow wave sleep from the hypoglycaemic period later at night. The sleep debt need not be restored hour per hour, since it is not compensated only by an increase of time spent in deep sleep, but also by more pronounced slow wave activity within this stage, i. e. an increased sleep intensity $[16,17]$. Thus, although the sleep was disturbed during hypoglycaemia, the patients were able to compensate for this disturbance to a degree that eliminated the expected influence on the performance in neuropsychological testing in the mornings.

In the present study blood glucose had been restored for at least $90 \mathrm{~min}$ at the time for neuropsychological testings. We were, by the use of simple tests, unable to describe significant differences in the performance. However, the possibility of a neutralization of cognitive dysfunction by an increasing learning effect has been considered. To reduce the possibility of a learning effect the test battery consists of different tasks testing the same functions differently. All tests call for attention and concentration. If the patient tries to improve his reaction time in these simple tests, he tends to increase the number of false reactions, which would be registered by the computer. The trail making, letter cancellation and digit span were chosen because they have very little learning effect; it takes a lot of training to increase the number of digits repeated correctly backwards when the patient is presented with new and random digit combinations for each test. In studies of acute hypoglycaemic impact with parallel sham studies we have used these tests without observing a learning effect $[1,18]$. In agreement with these results we are unable to describe a general learning effect in our present study. The fact that no disturbance is found in cognitive function after at least 90 min after restoration of the blood glucose is in accordance with previous findings of the acute cerebral dysfunction during hypoglycaemia. However, previous studies were all per formed during daytime, hence the possible influence of sleep disturbances is a new contribution. Since nocturnal hypoglycaemia appears in $29-56 \%$ of insulin-dependent diabetic patients with a duration of $1-12 \mathrm{~h}$, most often without symptoms $[7,8,19-23]$ it is important that daytime performance was not affected.

Acknowledgements. We are grateful to Dr. G.Wildschiødtz for allowing us to perform the studies at the Sleep Laboratory, University Hospital Glostrup, Denmark. 


\section{References}

1. Pramming S, Thorsteinsson B, Theilgaard A, Pinner EM, Binder C (1986) Cognitive function during hypoglycaemia in Type 1 diabetes mellitus. Br Med J 292: 647-650

2. Holmes CS, Tsalikan E, Yamada T (1988) Blood glucose control and visual and auditory attention in men with insulin-dependent diabetes. Diabetic Med 5: 634-639

3. Tallroth G, Lindgren M, Stenberg G, Rosen I, Agardh C-D (1990) Neurophysiological changes during insulin-induced hypoglycaemia and in the recovery period following glucose infusion in type 1 (insulin-dependent) diabetes mellitus and in normal man. Diabetologia 33: 319-323

4. Wredling R, Levander S, Adamson U, Lins P-E (1990) Permanent neuropsychological impairment after recurrent episodes of severe hypoglycaemia in man. Diabetologia 33: 152-157

5. Ryan C, Vega A, Drash A (1985) Cognitive deficits in adolescents who developed diabetes early in life. Pediatrics 25: 748-765

6. Rovet FJ, Ehrlich MR, Hoppe M (1987) Intellectual deficits associated with early onset of insulin-dependent diabetes mellitus in children. Diabetes Care 4:510-515

7. Bendtson I, Gade J, Thomsen CE, Rosenfalck A, Wildschiødtz G (1992) Sleep disturbances in IDDM patients with nocturnal hypoglycemia. Sleep 15: 74-81

8. Bendtson I, Gade J, Rosenfalck AM, Wildschiødtz G, Binder C (1991) Nocturnal electroencephalogram registrations in type 1 (insulin-dependent) diabetic patients with hypoglycaemia. Diabetologia 34: 750-756

9. Kischinovsky G, Jennum P, Mortensen EL, Wildschiødtz G (1987) Cognitive impairment in obstructive sleep apnea syndrome. Sleep Research 16:370 (Abstract)

10. Haraldson P-O, Carenfeldt C, Diderichsen F, Nygren A, Tingvall C (1990) Clinical symptoms of sleep apnea syndrome and automobile accidents. ORL 52: 57-62

11. Ovesen J, Würtzen Nielsen P, Wildschiødtz G (1991) Shortened reaction time during nasal CPAP treatment of obstructive sleep apnea. Acta Otolaryngol (Stockh) 492 [Suppl]: 119-121

12. Broughton R (1982) Performance and evoked potentials measures of various states of daytime sleepiness. Sleep 5: 135146
13. Lisper H-O, Kjellberg A (1972) Effects of 24 hour sleep deprivation on rate of decrement in a 10-minute auditory reaction time task. J Exp Psychol 96: 287-290

14. Rechtschaffen A, Kales A (1968) A manual of standardized terminology, techniques and scoring systems for sleep stages of human subjects. US Government Printing office, Washington

15. Dement WC, Kleitman N (1957) Cyclic variation in EEG during sleep and their relation to eye movements, body motility, and dreaming. Electroencephalogr Clin Neurophysiol 9: 673-690

16. Borbély AA (1982) A two process model of sleep regulation. Hum Neurobiol 1: 195-204

17. Ảkerstedt T, Gillberg M (1981) The circadian variation of experimentally displaced sleep. Sleep $4: 159-169$

18. Bendtson I, Theilgaard A, Sørensen HH, Binder C (1989) The hypoglycaemic effects of equimolar quantities of semisynthetic human and porcine insulin in insulin-dependent diabetic patients. Ugeskr Læger 151:3163-3166

19. Gale EAM, Tattersall R (1979) Unrecognized nocturnal hypoglycaemia in insulin treated diabetics. Lancet I: 1049-1052

20. Dornan T, Peckar C, Mayon-White V et al. (1981) Unsuspected hypoglycaemia, hemoglobin A1, and diabetic control. Quart J Med 197: 31-38

21. Winter R, Stone N, Wise J et al. (1979) Standard parameters of diabetic control: are they reliable? Diabetes Care $2: 336-341$

22. Pramming S, Thorsteinsson B, Bendtson I, Rønn B, Binder C (1985) Nocturnal hypoglycaemia in patients receiving conventional treatment with insulin. Br Med J 291:376-379

23. Bendtson I, Kverneland A, Pramming S, Binder C (1988) Incidence of nocturnal hypoglycaemia in insulin-dependent diabetic patients on intensive therapy. Acta Med Scand 223: 543 548

Received: 2 March 1992

and in final revised form: 29 May 1992

Dr. I. Bendtson

Steno Diabetes Center

2, Niels Steensensvej

DK-2820 Gentofte

Denmark 